\title{
Deus, Filho e Espírito humano na Milonga Del Moro Judío
}

\author{
Tony Roberson de Mello Rodrigues
}

\section{SciELO Books / SciELO Livros / SciELO Libros}

FERRAZ, S., et al.,orgs. Deuses em poéticas: estudos de literatura e teologia [online]. Belém: UEPA; Campina Grande: EDUEPB, 2008. 364 p. ISBN 978-85-7879-010-3. Available from SciELO Books $<\underline{\text { http://books.scielo.org }>\text {. }}$

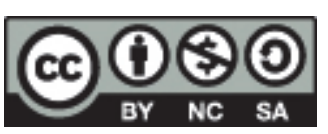

All the contents of this work, except where otherwise noted, is licensed under a Creative Commons Attribution-Non Commercial-ShareAlike 3.0 Unported.

Todo o conteúdo deste trabalho, exceto quando houver ressalva, é publicado sob a licença Creative Commons Atribuição Uso Não Comercial - Partilha nos Mesmos Termos 3.0 Não adaptada.

Todo el contenido de esta obra, excepto donde se indique lo contrario, está bajo licencia de la licencia Creative Commons Reconocimento-NoComercial-CompartirIgual 3.0 Unported. 


\title{
Deus, Filho e Espírito Hu- mano na Milonga Del Moro Judío
}

\author{
Tony Roberson de Mello Rodrigues
}




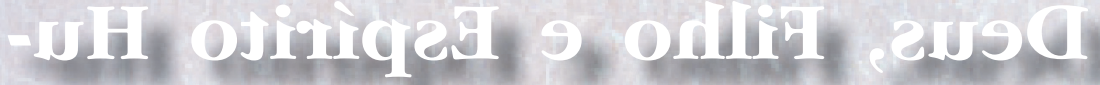

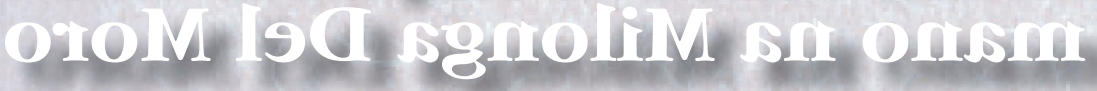 oibul}

zanginbor olfom ab moznodos conol. 
Rodrigues, Tony Roberson de Mello*

Resumo: Artista uruguaio com discografia reconhecida internacionalmente, o compositor Jorge Drexler trabalha vários temas nas músicas de $\mathrm{ECO}^{2}$, CD lançado em 2004. Uma delas é a Milonga Del MoroJudío, a qual selecionamos para analisar como a temática da existência de Deus é trabalhada nesta música. Buscaremos demonstrar como o tipo de música utilizado (milonga), o "eu lírico" presente e as ocorrências da palavra "Deus" na letra relacionam-se e tornam possível uma teopoética construída basicamente por valores humanos.

Palavras-chave: Milonga, Teopoética, Jorge Drexler.

Abstract: A Uruguayan artist with an internationally recognized discography, composer Jorge Drexler works several themes in the music of $E C^{2}$, a CD released in 2004. One of them is the Milonga Del Moro Judio, which we selected in order to examine how the theme of God's existence is worked in this music. We will demonstrate how the musical genre used ("milonga"), the present "lyric I" and the occurrences of the word "God" in the music's lyrics interrelate and make possible a theopoetic built upon human values.

Keywords: Milonga, Theopoetic, Jorge Drexler.

* Graduando em Letras - Português pela Universidade Federal de Santa Catarina (UFSC). Linhas de pesquisa: pesquisador voluntário no Núcleo de Estudos Comparados entre Teologia e Literatura (NUTEL), coord. pela prof ${ }^{a}$. Dra. Salma Ferraz; pesquisador CNPq no Núcleo de Pesquisas em Informática, Literatura e Lingüística (NUPILL), coord. pelo prof. Alckmar Luiz dos Santos, ambos na UFSC; revisor, redator técnico e poeta. E-mail: tudosimples@gmail.com 


\section{Cristianismo e Milonga}

As parábolas e ensinamentos atribuídos a Jesus Cristo na Bíblia de origem judaico-cristã ${ }^{169}$ demonstram facilmente a tradição oral com que esse Jesus ensinava e o caráter popular de suas pregações, através do uso pedagógico das parábolas ${ }^{170}$. Essa mesma tradição oral e de caráter popular podemos observar musicalmente nas festividades dos Centros de Tradição Gaúcha (CTGs) no sul do Brasil e nos repentistas da região nordeste.

$\mathrm{Na}$ região sul, beirando as fronteiras geográficas com a Argentina, o Paraguai e o Uruguai, vê-se muitas vezes a convivência de diversas culturas regionais. Na música, tomemos os exemplos do Chamamé, da Vaneira, do Tango e da Milonga. Mas o que seria a Milonga?

Conforme Maria de Los Ángeles Jiménez García em Minidicionário de espanbol (2000, p. 272), a milonga pode ser entendida como "canto y danza popular de Argentina y Uruguay". Para Aurélio Buarque de Hollanda Ferreira, no dicionário Miniaurélio Século XXI (2000, p. 463), a milonga é "certa música platina, dolente, cantada ao som do violão". Segundo o Diccionario de la Musica (1981), a milonga é vista como um

"canto popular muy corriente em las repúblicas sudamericanas, que se canta con acompañamento de guitarra. [...] Su especto musical es el de una canción somnolenta, de movimiento lento, proveniente de la forma rítmica de su acompañamiento." (1981, p. 321).

Na canção "Milonga Del Moro Judío", do compositor uruguaio Jorge Drexler ${ }^{171}$, a tradição oral é retomada pelo estilo milonga com a presença de um cantador (o eu lírico do poema, el milonguero) e de seu violão.

169 Para o presente estudo utilizamos a Bíblia Sagrada traduzida para o português por João Ferreira de Almeida (1989).

170 Sobre o caráter pedagógico das parábolas, sugerimos a leitura da entrevista "Por uma pedagogia da palavra", concedida pelo rabino Henry Isaac Sobel à revista PROLEITURA em junho de 1997. O artigo encontra-se referenciado ao final do presente artigo.

171 Para mais informações sobre a discografia e premiações atribuídas ao compositor, sugerimos o acesso ao site http://www.jorgedrexler.com/ 
Observamos $^{172}$ que o movimento originariamente lento cede espaço a um movimento envolvente, mais rápido. Não adentraremos a área de estudos comparados de literatura e música para analisar como essa diferenciação é construída, porém defendemos que a escolha do ritmo milonga foi de fundamental importância na caracterização do eu lírico do poema, ou seja, de alguém que necessita repassar, através da tradição oral, uma mensagem às pessoas. Seria Jesus?

\section{O eu lírico da milonga}

A composição de Drexler trabalha a figura de um milonguero acompanhado de um violão que busca através da cultura popular cantada repassar determinadas mensagens, utilizando para isso um vocabulário comum, porém de extrema beleza poética.

Lembramos que não estamos tratando de um poema, mas de uma letra de música, e não saberíamos distinguir se a presente composição trata-se, nas palavras de Ezra Pound em $O A B C$ da Literatura (2007, p. 11), de uma melopéia, fanopéia, logopéia ou de ambos os casos, mas podemos emprestrar dos estudos de poesia o termo "eu lírico" para compreender esse personagem a partir de como ele foi construído poeticamente.

$\mathrm{Na}$ letra analisada, percebemos que o compositor constrói muitos versos que remetem a um contexto religioso e de caráter pedagógico, para com o qual o eu lírico (Jesus Cristo) parece identificar-se.

Já nos dois primeiros versos da primeira estrofe faz-se um trocadilho com o muro das lamentações, em Jerusalém: "Por cada muro um lamento / Em Jerusalém la dorada". Em seguida aborda-se os mandamentos e o eu lírico direciona sua mensagem às pessoas através do pronome "tu" nos versos "Yo soy polvo de tu viento / Y aunque sangro de tu herida". A partir de "aunque" apresenta-se um julgamento de valores cuja síntese se revela nos dois últimos versos dessa primeira estrofe: "No hay una piedra en el mundo / Que valga lo que una vida".

Na seqüência desse primeiro julgamento de valores apresenta-se o estribilho, em que a caracterização do eu lírico é retomada: "Yo soy um moro judio / Que vive con los cristianos, / No sé que dios es el mío

172 Artigo apresentado em 11 de outubro de 2007 no congresso internacional Terceras Jornadas: Diálogos entre Literatura, Estética y Teologia, promovido pelas faculdades de Filosofía e Letras e de Teologia da Pontifícia Universidade Católica Argentina, em Buenos Aires. 


\section{/ Ni cuales son mis hermanos."}

Apesar de estabelecer mais informações sobre quem seja esse milonguero que canta a música, ainda aqui não está claro que o eu lírico que canta seja esse Jesus. Na segunda estrofe, o eu lírico retoma sua abordagem pedagógica para posicionar-se contra a guerra e, nos dois últimos versos dessa estrofe, retoma-se a síntese de valores com os quais esse eu lírico se identifica: "Vale más qualquier quimera / Que um trozo de tela triste."

A terceira estrofe da milonga apresenta-se como o momento de epifania, de revelação: a voz do cantor sobressai aos instrumentos, fica em primeiro plano, como se ele se aproximasse mais de seu público para apresentar algo de mais importante ainda em sua mensagem. Essa abordagem se desenvolve do primeiro ao quinto verso dessa estrofe, pois, no início do sexto verso, junto à palavra seguirá são retomados em primeiro plano novamente os instrumentos musicais, paralelamente à voz do cantor. Seria Jesus?

Com os dois primeiros versos da última estrofe, podemos enfim interpretar o eu lírico da canção como Jesus Cristo, quando afirma que "Y a nadie le dí permisso / Para matar em mi nombre". Um Cristo com ensinamentos a pregar às multidões através da oralidade musical, espiritualizado e acima de tudo humano, que aconselha, que se mostra triste com a guerra, que nos relembra a importância de sonhar, um Jesus que concorda e discorda dos homens na medida em que nos revela os valores que movem seu coração.

O estribilho da música nos relembra, inclusive, um Jesus comum, sem respostas metafóricas ou grandes certezas a anunciar à humanidade, elevado moral e espiritualmente, porém sem a necessidade de uma concepção divinista. Com relação à idéia de Deus, seria esse Jesus um Jesus ateu, politeísta ou apenas indeciso?

\section{O Deus Humano}

A palavra "dios" aparece apenas duas vezes na milonga de Drexler. No estribilho, demonstra que o eu lírico (Jesus) não está certo sobre qual deus seja o seu: "No sé que dios es el mio". Na última estrofe da milonga, a palavra "dios" aparece para representar um ser cuja existência ainda não é totalmente certa para esse Jesus e que, caso exista, é um Deus que deseja mais fraternidade entre os homens, um deus que existe na medida em que deseja a mesma fraternidade que esse Jesus 
deseja, sem guerras nem mortes: "Un hombre no es más que un bombre / Y si hay dios así lo quiso.”

Drexler constrói assim um Jesus humano que acredita na possibilidade da existência de um Deus também humano. Estaria, assim, Deus mais próximo dos homens que estariam mais próximos desse Jesus a pregar seus valores. Deus, Filho e Espírito Humano mais próximos de uma comunhão para além do numinoso.

\section{Considerações finais}

Não poderíamos deixar de abordar, ainda que brevemente e mesmo como sugestão para pesquisas futuras, um detalhe que muito nos chamou à atenção durante as várias vezes em que ouvimos a música cuja letra é aqui analisada. Trata-te das palavras "nombre" e "hombre", a forma como essas palavras estão inseridas em um trecho específico da música e as possibilidades de interpretação que podemos fazer a partir do momento em que ouvimos esse trecho da música na última estrofe: "Y a nadie le dí permiso / Para matar en mi nombre, / Un bombre no es más que un hombre / Y si hay dios así lo quiso."

$\mathrm{Na}$ língua espanhola, as palavras "hombre" e "nombre" são muito parecidas na escrita e na pronúncia. Quando pronunciadas separadamente, pode-se perceber mais claramente a diferença entre o " $h$ " e o " $n$ " com que estas palavras iniciam, porém no verso da milonga em que está inserida a palavra "hombre" a diferença de pronúncia torna-se mais sutil sonoramente, de forma que o trecho "Un bombre no es más que um bombre" pode ser ouvido também como "Un nombre no es más que un nombre", ou ainda, como preferimos sugerir, "Un hombre no es más que un nombre", pois assim o verso sugere não apenas a igualdade que o Jesus lírico propõe entre os homens, mas relembra a efemeridade da vida à qual todos nós estamos sujeitos e que o compositor (Drexler) sabiamente pincela nas estrofes de sua milonga, a qual nos parece, após tantas vezes escutada, um hino de amor e honra à brevidade com que a vida de cada ser humano nasce, brota e desabrocha em flor. 


\section{Referências}

. Bíblia Sagrada. Tradução de João Ferreira de Almeida. Brasília:

Sociedade Bíblica do Brasil, 1989.

. Diccionario de la Musica. $4^{\mathrm{a}}$ edición. Editorial Iberia S.A. Espanha: Barcelona, septiembre 1981.

FERREIRA, Aurélio Buarque de Hollanda. Miniaurélio Século XXI: O minidicionário da língua portuguesa. $4^{\mathrm{a}}$ ed. rev. e ampliada. Rio de Janeiro: Nova Fronteira, 2000.

GARCÍA, Maria de Los Ángeles Jiménez. Minidicionário de espanhol: três em um: espanhol-espanhol, espanhol-português, português-espanhol. São Paulo: Scipione, 2000.

POUND, Ezra. ABC da Literatura. Tradução de Augusto de Campos e José Paulo Paes. São Paulo: Editora Cultrix, 16 ${ }^{\mathrm{a}}$ Edição, 2007.

UNESP. Por uma pedagogia da parábola. In: PROLEITURA, ano $4, \mathrm{n}^{\circ}$ 14. São Paulo: UNESP, junho de 1997. 